ASIMTOT: JURNAL KEPENDIDIKAN MATEMATIKA

Volume 2 Nomor 2, Juni - November 2020, halaman 153 - 159

Tersedia Daring pada https://journal.unwira.ac.id/index.php/ASIMTOT

\title{
PENGARUH KEMANDIRIAN BELAJAR DAN MINAT BELAJAR TERHADAP PRESTASI BELAJAR MATEMATIKA SISWA SMA
}

\author{
Rosalia Fransiska Ina Ledun ${ }^{1}$, Agapitus H. Kaluge ${ }^{2}$, Aloysius Joakim Fernandez ${ }^{3}$ \\ ${ }_{1,2,3}$ Program Studi Pendidikan Matematika UNWIRA \\ inaledunrosalia@gmail.com ${ }^{1}$,agapituskaluge@gmail.com ${ }^{2}$, fndz1586@ gmail.com ${ }^{3}$
}

\begin{abstract}
Abstrak: Tujuan dari penelitian ini untuk mengetahui pengaruh kemandirian belajar dan minat belajar siswa SMA. Jenis dari penelitian ini yaitu penelitian kuantitatif dengan menggunakan analisis regresi berganda. Sampel dalam penelitian ini kelas XI IIS yang berjumlah 34 orang yang dipilih secara acak. Jenis datanya yaitu data primer. Alat pengumpulan data yang digunakan yaitu angket dan tes prestasi belajar matematika. Teknis analisis data dalam penelitian ini menggunakan analisis regresi ganda. Berdasarkan hasil uji parsial pada kemandirian belajar menunjukkan bahwa $t_{\text {hitung }}=2,816>2,040=t_{\text {tabel }}$ sehingga kemandirian belajar mempunyai pengaruh terhadap prestasi belajar matematika dan pada minat belajar diperoleh $t_{\text {hitung }}=2,006<$ $2,040=t_{\text {tabel }}$ sehingga ada pengaruh yang tidak signifikan minat belajar terhadap prestasi belajar matematika. Selanjutnya, pada uji secara simultan menunjukkan bahwa $F_{\text {hitung }}=8,680>3,30=F_{\text {tabel }}$ maka terdapat pengaruh simultan pada kemandirian belajar dan minat belajar terhadap prestasi belajar matematika. Dengan demikian dapat disimpulkan bahwa ada pengaruh kemandirian belajar dan minat belajar terhadap prestasi belajar matematika
\end{abstract}

Kata Kunci: kemandirian belajar, minat belajar, prestasi belajar matematika

\begin{abstract}
This study aims to determine the effect of self-reliance learning and high school students' learning interest. This type of research is quantitative research with statistical analysis used is multiple regression analysis. The sample in this study class XI IIS, amounting to 34 people selected at random. The type of data in this research is primary data with data collection used, namely questionnaire and achievement test questions. Technical analysis of the data in this study used multiple regression analysis. Based on the partial test results on self-reliance shows that $t_{\text {count }}=2,816>2,040=t_{\text {table }}$ so that self-reliance has an effect on mathematics learning achievement and the learning interest obtained $t$ count $=2,006<2,040=t$ table so that there is no significant effect of learning interest on learning achievement mathematics. Furthermore, the simultaneous test shows that $F_{\text {count }}=8.680>3.30=F_{\text {table }}$ then there is a simultaneous influence on self-reliance and interest in learning towards mathematics learning achievement. Thus it was concluded that there was an effect of selfreliance and interest in learning towards mathematics learning achievement.
\end{abstract}

Keywords: Self-reliance, interst learning, achievemnt learn

Cara Sitasi: Ledun, I.F. R., Kaluge, H. A.,\& Fernandez, J.A. (2020). Pengaruh Kemandirian Belajar Dan Minat Belajar Terhadap Prestasi Belajar matematika Siswa SMA. Asimtot: Jurnal Kependidikan Matematika, “2”(“2”), "153-159" 
ASIMTOT: JURNAL KEPENDIDIKAN MATEMATIKA

Volume 2 Nomor 2, Juni - November 2020, halaman 153 - 159

Tersedia Daring pada https://journal.unwira.ac.id/index.php/ASIMTOT

Pendidikan merupakan kebutuhan penting dan fundamen bagi kehidupan setiap individu. Melalui pendidikan yang dijalani, individu mampu memberikan sumbangsi bagi negara dan menemukan kualitas hidup yang mapan dan bernilai demi keberlanjutan kehidupan masa depannya. Kualitas pendidikan seseorang ditentukan oleh proses pembelajaran yang dialami, dalam artian bahwa jika proses belajar baik maka hasil atau prestasi yang akan dicapai baik adanya dan sebaliknya jika dalam proses pembelajaran individu tidak menjalankannya dengan baik maka akan menuai hasil atau prestasi yang buruk. Aktivitas pembelajaran yang baik ditentukan pula oleh kemandirian dalam belajar dari setiap individu dan juga minat belajar dalam proses pembelajaran yang mampu memberikan makna tersendiri bagi setiap individu yang menjalani proses pembelajaran.

Pembelajaran bermakna dan bisa mengaktifkan siswa adalah pembelajaran yang didasarkan pada pengalaman yang mengesankan. Matematika merupakan salah satu mata pelajaran yang menarik. Tujuan mempelajari matematika agar dapat membentuk karakter siswa dalam menganalisis soal dan mempersiapkan siswa menghadapi kehidupan yang terus berkembang dengan kemampuan bertindak dan bernalar secara kritis, logis dan sistematis serta efisien dan efektif serta mampu menyampaikan ide-ide secara lisan (Puskur, 2002). Pendidikan yang berkesan dan berkualitas ditentukan pula oleh tingginya prestasi belajar yang diperoleh.
Prestasi belajar dapat dipandang sebagai hasil pengukuran dan penilaian hasil belajar yang telah dilakukan oleh siswa setelah mereka melakukan kegiatan proses pembelajaran yang kemudian dibuktikan dengan suatu tes dan hasil pembelajaran tersebut dinyatakan dalam bentuk simbolik baik dalam bentuk angka, huruf maupun kalimat yang menceritakan hasil belajar yang sudah dicapai. Prestasi belajar adalah tingkat keberhasilan siswa dalam mencapai tujuan yang ditetapkan dalam sebuah program (Syah, 2010). Prestasi belajar tingkat keberhasilan siswa dalam belajar yang diketahui dalam bentuk tes dan ditunjukkan dalam bentuk nilai (Abineno, Rowa, \& Jagom, 2019).

Dalam kegiatan pembelajaran, untuk mencapai prestasi belajar yang optimal diperlukan juga kemandirian dalam belajar dan juga minat atau motivasi dalam belajar. Kemandirian belajar memampukan siswa untuk tidak memiliki ketergantungan pada orang lain dan terlibat aktif dalam setiap proses pembelajan serta memiliki inisiatif sendiri dalam belajar matematika. Menurut Sumarno, melalui kemandirian yang baik dalam belajar, siswa mampu memantau, mengevaluasi, dan mengatur waktu belajarnya secara efektif dan efisien, serta mampu mengarahkan dan mengendalikan diri sendiri dalam berpikir dan bertindak, serta tidak merasa bergantung pada orang lain secara emosional (Sumarmo, 2002). Sedangkan minat merupakan perpaduan keinginan dan kemauan yang dapat berkembang jika ada motivasi. Minat dapat membantu siswa membangkitkan perasaan ingin tahu dan 


\section{ASIMTOT: JURNAL KEPENDIDIKAN MATEMATIKA}

\section{Volume 2 Nomor 2, Juni - November 2020, halaman 153 - 159}

Tersedia Daring pada https://journal.unwira.ac.id/index.php/ASIMTOT

kesenangan atau kenikmatan. Minat dapat membuat seseorang menjadi termotivasi untuk mempelajarinya dan menunjukan kinerja yang tinggi. Minat dapat bersifat relatif menetap pada diri seseorang. Minat besar sekali pengaruhnya terhadap kegiatan seseorang sebab dengan minat ia akan melakukan sesuatu (Makmun, 2013).

Usaha kemandirian dalam belajar bila didukung dengan minat atau motivasi belajar yang baik dapat membantu siswa untuk mencapai prestasi belajar yang optimal. Pada kenyataanya, masih banyak siswa yang belum mampu mengatur atau mengarahkan dirinya sendiri dalam belajar. Kemandirian dan juga minat dalam pembelajaran sering disepelehkan sehingga siswa sering merasakan kurangnya motivasi dalam dirinya sendiri yang dapat menimbulkan sikap malas dalam belajar, malas untuk berpartisipasi dalam kelas dan juga siswa berpendapat bahwa akan tetap bisa lulus ataupun naik kelas dengan mudah meskipun dengan nilai dibawah rata-rata.

Berdasarkan pengalaman PPL di SMAN 7 Kupang, prestasi belajar matematika siswa sangat beragam. Beberapa siswa memiliki prestasi belajar matematika rendah dan beberapa siswa lain memiliki prestasi belajar matematika yang tinggi. Rendahnya prestasi belajar siswa dikarenakan kurangnya kemandirian dalam belajar dan juga kurangnya minat atau motivasi dari dalam diri untuk mempelajari pelajaran matematika. Semantara tingginya prestasi belajar matematika yang diperoleh beberapa siswa dipengaruhi oleh tingginya minat dalam belajar yang didukung pula melalui kemandirian dalam belajar sehingga prestasi belajar matematika siswa menjadi tinggi. Kemandirian belajar yang tinggi dan disertai minat belajar yang baik dapat membantu siswa mencapai prestasi belajar matematika yang memuaskan.

Dari uraian di atas, peneliti ingin mengetahui pengaruh kemandirian belajar dan minat belajar terhadap prestasi belajar matematika. Oleh karena itu peneliti melakukan penelitian dengan judul 'pengaruh kemandirian belajar dan minat belajar terhadap prestasi belajar matematika siswa SMA".

\section{Metode Penelitian}

Penelitian merupakan penelitian kuantitatif yang menggunakan analisis regresi berganda.

Penelitian ini dilaksanakan di kelas XI IIS SMA N 7 Kupang tahun ajaran 2019/2020. Sampelnya 34 siswa, yang dipilih secara random. Data dalam penelitian ini yaitu data primer yang diperoleh melalui pengisian angket dan hasil tes yang diambil secara langsung oleh peneliti.

Pengujian dalam penelitian ini meliputi uji normalitas, uji linearitas, uji multikolinearitas, serta uji $\mathrm{t}$ dan uji $\mathrm{F}$ dalam analisis regresi berganda. 


\section{ASIMTOT: JURNAL KEPENDIDIKAN MATEMATIKA}

\section{Volume 2 Nomor 2, Juni - November 2020, halaman 153 - 159}

Tersedia Daring pada https://journal.unwira.ac.id/index.php/ASIMTOT

\section{Hasil Penelitian dan Pembahasan}

\section{Hasil}

Ada 3 uji prasyarat atau uji asumsi klasik yang dilakukan yaitu uji normalitas, uji linearitas, dan uji multikolinearitas.

\section{Uji Normalitas}

Pengujian normalitas data dilakukan menggunakan Kolmogorov Smirnov test. Pengujiannya dengan membandingkan nilai $\mathrm{D}_{\text {hitung }}$ dan $\mathrm{D}_{\text {tabel }}$ pada taraf signifikansi $5 \%$ yaitu:

Jika $\mathrm{D}_{\text {hitung }}<\mathrm{D}_{\text {tabel }}$ maka terima Ho yaitu data berdistribusi normal. Jika tidak memenuhi maka Ho ditolak artinya data tidak berdistribusi normal

Tabel 1. Uji normalitas

\begin{tabular}{|l|c|c|c|}
\hline \multicolumn{1}{|c|}{ Variabel } & $\begin{array}{c}\text { Tes } \\
\text { statistic }\end{array}$ & $\begin{array}{c}\text { Asymp. } \\
\text { Sig. } \\
(2 \text { tailed } \\
)\end{array}$ & \multicolumn{1}{|c|}{ Ket. } \\
\hline $\begin{array}{l}\text { Kemandirian } \\
\text { belajar }\end{array}$ & 0,154 & 0,393 & $\begin{array}{c}\text { Berdistribusi } \\
\text { normal }\end{array}$ \\
\hline Minat belajar & 0,162 & 0,335 & $\begin{array}{c}\text { Berdistribu } \\
\text { si normal }\end{array}$ \\
\hline $\begin{array}{l}\text { Prestasi } \\
\text { belajar }\end{array}$ & 0,099 & 0,892 & $\begin{array}{c}\text { Berdistribu } \\
\text { si normal }\end{array}$ \\
\hline
\end{tabular}

Berdasarkan analisis menggunakan

SPSS 22.0 for windows di atas, diperoleh nilai signifikansi $=0,393$. Nilai ini $0,393>0,05$ maka $\mathrm{H}_{0}$ diterima yang berarti data kemandirian belajar berdistribusi normal. Berdasarkan hasil analisis dari SPSS 22.0 for windows nilai $\mathrm{D}_{\text {hitung }}=0,154<$ nilai $\mathrm{D}_{\text {tabel }}=$ 0,224 dengan $\alpha=0,05$ dan $n=34$. Hal ini berarti data kemandirian belajar berdistribusi normal.

Hasil uji normalitas pada variabel $\mathrm{X}_{2}$ (minat belajar) melalui output SPSS 22.0 for windows, diperoleh nilai signifikansi $=$ 0,335 . Oleh karena nilai signifikan $=$ $0,335>0,05$ maka $\mathrm{H}_{0}$ diterima yang berarti data minat belajar berdistribusi normal. Berdasarkan hasil output SPSS 22.0 for windows juga menunjukan nilai $\mathrm{D}_{\text {hitung }}=$ $0,162<$ nilai $\mathrm{D}_{\text {tabel }}=0,224$ dengan $\alpha=0,05$ dan $n=34$ berarti data minat belajar berdistribusi normal.

Hasil uji normalitas pada variabel $\mathrm{Y}$ (Prestasi belajar Matematika) melalui output SPSS 22.0 for windows diperoleh nilai signifikansi $=0,892$. Oleh karena nilai signifikan $=0,982>0,05$ maka $\mathrm{H}_{0}$ diterima berarti data prestasi belajar matematika berdistribusi normal. Berdasarkan hasil output SPSS 22.0 for windows juga menunjukan bahwa nilai $\mathrm{D}_{\text {hitung }}=0,099<$ nilai $\mathrm{D}_{\text {tabel }}=$ 0,224 dengan $\alpha=0,05$ dan $n=34$ maka data minat belajar berdistribusi normal.

\section{Uji Linearitas}

Adapun kriteria pengujiannya, yaitu dengan membandingkan nilai Fhitung dan Ftabel pada taraf signifikansi 5\% yaitu :

jika $F_{\text {hitung }} \leq \mathrm{F}_{\text {tabel}}$, maka data berpola linear

jika $F_{\text {hitung }} \geq F_{\text {tabel }}$, maka data tidak berpola linear.

\begin{tabular}{|c|c|c|l|l|}
\hline $\begin{array}{c}\text { Variabel X } \\
\text { terhadap Y }\end{array}$ & $\mathrm{F}_{\text {hitung }}$ & $\mathrm{F}_{\text {tabel }}$ & Sig. & Ket. \\
\hline $\begin{array}{l}\text { X1 terhadap } \\
\text { Y }\end{array}$ & 0,906 & 2,33 & 0,577 & Linear \\
\hline
\end{tabular}




\section{ASIMTOT: JURNAL KEPENDIDIKAN MATEMATIKA}

\section{Volume 2 Nomor 2, Juni - November 2020, halaman 153 - 159}

Tersedia Daring pada https://journal.unwira.ac.id/index.php/ASIMTOT

\begin{tabular}{|l|l|l|l|l|}
\hline $\begin{array}{l}\mathrm{X} 2 \text { terhadap } \\
\mathrm{Y}\end{array}$ & 1,335 & 2,39 & 0,289 & Linear \\
\hline
\end{tabular}

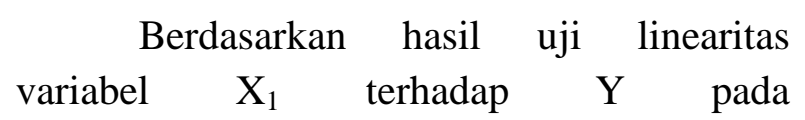
output SPSS 22.0 for windows, diperoleh nilai signifikansi pada Deviation from Linearity sebesar 0,577 >0,05 maka dapat katakan bahwa data yang menunjukan hubungan antara variabel $\mathrm{X}_{1}$ dan $\mathrm{Y}$ berpola linear. Pada hasil analisis melalui SPSS 22.0 for windows diketahui nilai $\mathrm{F}_{\text {hitung }}=0,906$ dengan $\alpha=0,05$, df1 $=16$ dan df $2=16$ maka nilai $F_{\text {tabel }}=2,33$. Karena $F_{\text {hitung }}=0,906<$ $\mathrm{F}_{\text {tabel }}=2,33$, maka dapat diartikan bahwa ada hubungan linear antara vareabel $\mathrm{X}_{1}$ dan $\mathrm{Y}$.

Berdasarkan hasil uji linearitas variabel $\mathrm{X}_{2}$ dengan $\mathrm{Y}$ melalui output SPSS 22.0 for windows nilai signifikansi pada Deviation from Linearity sebesar 0,289> 0,05 maka dapat diartikan bahwa ada hubungan yang linear antar $\mathrm{X}_{2}$ dan $\mathrm{Y}$. Pada hasil analisis melalui output SPSS 22.0 for windows, diketahui nilai $\mathrm{F}_{\text {hitung }}=1,335$ dengan $\alpha=0,05$, df $1=17$ dan df $2=15$ maka nilai $\mathrm{F}_{\text {tabel }}=2,39$. Karena $\mathrm{F}_{\text {hitung }}=1,335 \leq$ $\mathrm{F}_{\text {tabel }}=2,39$ maka dapat diartikan bahwa ada hubungan linear antara variabel $\mathrm{X}_{2}$ dan $\mathrm{Y}$.

\section{Uji Multikolinearitas}

Uji multikoliearitas data pada program SPSS 22.0 for windows menggunakan VIF. Kriteria pengujiannya adalah :

Jika nilai VIF $<10$ maka tidak ada multikolinearitas antara kedua variabel bebas dan jika nilai VIF $\geq 10$ maka ada multikolinearitas antar kedua variabel bebas.
Prasyarat yang harus dipenuhi dalam persamaan regresi yaitu tidak terjadi multikolinearitas.

Berdasarkan hasil analisis melalui output SPSS 22.0 for windows uji multikolinearitas variabel $\mathrm{X}_{1}$ dan $\mathrm{X}_{2}$ adalah $1,030<10$ maka dapat disimpulkan bahwa tidak terjadi multikolinearitas.

\section{Analisis Regresi Berganda}

Dari hasil analisis regresi berganda melalui SPSS 22.0 for windows diperoleh besarnya kontribusi atau sumbangan variabel $\mathrm{X}_{1}$ dan variabel $\mathrm{X}_{2}$ terhadap variabel $\mathrm{Y}$ pada sebesar $30,4 \%$ dan sisanya $60,6 \%$ disumbangkan ke variabel lain di luar penelitian. Dari hasil analisis regresi berganda antara variabel $X_{1}$ dan variabel $X_{2}$ terhadap variabel $\mathrm{Y}$ melalui output SPSS 22.0 for windows, diperoleh nilai a (constant) = $-24,920, b_{1}$ ( koefisien regresi) $=0,784$ dan $\mathrm{b}_{2}$ ( koefisien rgeresi) $=0,565$ dan $\mathrm{F}_{\text {hitung }}$ $=6,756$ dengan $\alpha=0,05, \quad$ df $1=2$ dan df2 $=31$ maka nilai $F_{\text {tabel }}=3,30$. Karena $\mathrm{F}_{\text {hitung }}=6,756>\mathrm{F}_{\text {tabel }}=3,30$ maka dapat disimpulkan ada pengaruh kemandirian belajar dan minat belajar terhadap prestasi belajar matematika. Dengan demikian persamaan regresinya sebagai berikut :

$$
\begin{gathered}
Y=a+b_{1} X_{1}+b_{2} X_{2} \\
Y=-24,920+0,784 X_{1}+0,565 X_{2}
\end{gathered}
$$

\section{Pembahasan}

Kemandirian dalam belajar merupakan aktivitas belajar yang keberlangsungannya lebih didorong oleh kemauan sendiri, pilihan 


\section{ASIMTOT: JURNAL KEPENDIDIKAN MATEMATIKA}

\section{Volume 2 Nomor 2, Juni - November 2020, halaman 153 - 159}

Tersedia Daring pada https://journal.unwira.ac.id/index.php/ASIMTOT

sendiri, dan tanggung jawab sendiri (Tirtarahardja,2008). Kemandirian belajar siswa dipengaruhi oleh beberapa faktor yakni : (1) Faktor Endogen: Faktor yang bersumber dari dirinya sendiri,dan (2) Faktor Eksogen: Faktor yang bersumber dari luar dirinya sendiri.

Minat merupakan masalah yang paling penting di dalam pendidikan, apalagi bila dikaitkan dengan aktivitas seseorang dalam kehidupan sehari-hari. Minat juga diartikan sebagai sifat yang relatif menetap pada diri seseorang. Minat besar sekali pengaruhnya terhadap kegiatan seseorang sebab dengan minat ia akan melakukan sesuatu (Makmun, 2013).Ada beberapa faktor yang mempengaruhi minat yaitu sebagai berikut:(1) The factor inner urge; (2) The factor of social motive ;(3) Emosional Factor.

Kemandirian belajar dan minat belajar berpengaruh terhadap prestasi belajar matematika siswa. Kemandirian siswa yang kuat tidak akan mudah menyerah. Sikap kemandirian dapat ditunjukan dengan adanya kemampuan dapat menyelesaikan masalah yang dihadapi dengan tingkah laku. Sedangkan seseorang memiliki minat yang tinggi untuk mempelajari suatu mata pelajaran maka ia akan mempelajarinya dalam jangka waktu tertentu untuk mencapai prestasi belajarnya. Dalam hubungannya dengan kegiatan belajar, minat belajar besar cenderung menghasilkan prestasi yang tinggi, sebaliknya minat belajar yang kurang akan menghasilkan prestasi yang rendah (Djamarah,2011)
Hasil penelitian menunjukan bahwa ada pengaruh secara parsial yang signifikan dari kemandirian belajar terhadap prestasi belajar matematika siswa SMA, ada pengaruh secara parsial yang tidak signifikan minat belajar terhadap prestasi belajar matematika siswa SMA dan ada pengaruh secara simultan yang signifikan dari kemandirian belajar dan minat belajar terhadap prestasi belajar matematika siswa SMA.

Berdasarkan hasil analisis ada pengaruh kemandirian belajar terhadap prestasi belajar matematika SMA $\mathrm{N} \quad 7$ Kupang. Hal ini ditunjukan dari hasil output SPSS 22.0 for windows nilai sig kemandirian belajar $0,008<0,05$ maka dapat disimpulkan bahwa ada pengaruh kemandirian belajar terhadap prestasi belajar matematika. Berdasarkan hasil analisis output SPSS 22.0 for windows, nilai sig. Minat belajar $=0,054>0,05$, maka dapat disimpulkan bahwa ada pengaruh yang tidak signifikan minat belajar terhadap prestasi belajar matematika.

Berdasarkan hasil analisis regresi berganda dapat diketahui bahwa ada pengaruh kemandirian belajar dan minat belajar terhadap prestasi belajar matematika. Terlihat pada hasil output SPSS 22.0 for windows uji $\mathrm{F}$ atau uji simultan bahwa nilai sig pada kemandirian belajar dan minat belajar yaitu $0,003<0,05$.

\section{Simpulan dan Saran}

\section{Simpulan}




\section{ASIMTOT: JURNAL KEPENDIDIKAN MATEMATIKA}

Volume 2 Nomor 2, Juni - November 2020, halaman 153 - 159

Tersedia Daring pada https://journal.unwira.ac.id/index.php/ASIMTOT

\begin{abstract}
Dari hasil analisis data dan pembahasan di atas maka peneliti dapat menyimpulkann bahwa kemandirian belajar dan minat belajar berengaruh terhadap prestasi belajar matematika siswa SMA.
\end{abstract}

\section{Saran}

Adapun rekomendasi bagi siswa, agar dapat menumbuhkan kemandirian belajar dan minat belajar dalam diri masing-masing. Sedangkan bagi guru matematika, agar lebih meningkatkan kemandirian belajar dan minat belajar kepada para siswa dalam kegiatan pembelajaran di kelas agar mencapai prestasi belajar yang maksimal.

\section{Daftar Pustaka}

Abineno, P., Rowa, R. Y., \& Jagom, O. Y. (2019). Pengaruh Model Pembelajaran Tutor Sebaya Terhadap Prestasi Belajar Matematika Siswa. Asimtot: Jurnal Kependidikan Matematika, 61 67.

Djamarah, S. B. (2011). Psikologi Belajar. Jakarta: Rineka Cipta.

Makmun, K. (2013). Psikologi Belajar. Asjawa Presindo.

Puskur. (2002). Kurikulum dan hasil belajar.Kompetensi dasar mata pelajaran matematika sekolah dasar dan madrasah Ibtidaiyah. Jakarta: Balitbang Depdiknas.

Sumarmo, U. (2002). Kemandirian Belajar: Apa, Mengapa, dan Bagaimana dikembangkan pada Peserta Didik Oleh: Utari Sumarmo, FPMIPA UPI. Academia.Edu. https://doi.org/10.1111/j.10958312.2011.01677.x

Syah, M. (2010). Psikologi Pendidikan dengan pendekatan baru. Bandung: PT Remaja Rosdakarya .

Tirtarahardja, U., \& Sulo, L. (2008). Pengantar Pendidikan. Rineka Cipta. 